\title{
Reduced Bone Mass in 7-Year-Old Children with Asymptomatic Idiopathic Hypercalciuria
}

\author{
Joaquin Escribano ${ }^{\mathrm{a}, \mathrm{b}}$ Carmen Rubio-Torrents ${ }^{\mathrm{a}}$ Natalia Ferréa \\ Veronica Luque $^{a, c}$ Veit Grote ${ }^{d}$ Marta Zaragoza-Jordana ${ }^{a}$

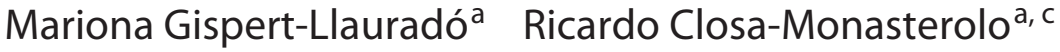 \\ for the European Childhood Obesity Project Group \\ anstitut d'Investigació Sanitaria Pere Virgili, Universitat Rovira i Virgili, and b Hospital Universitari \\ Sant Joan de Reus, Reus, and ' Hospital Universitari de Tarragona Joan XXIII, Tarragona, Spain; \\ dHauner Children's Hospital, University of Munich Medical Centre, Munich, Germany
}

\section{Key Words}

Idiopathic hypercalciuria - Bone mineral density · Children

\begin{abstract}
Background: Idiopathic hypercalciuria (IHC), i.e. an elevated urinary calcium excretion without concomitant hypercalcemia, is a common disorder in children and can have a range of urinary clinical presentations and decreased bone mineral density (BMD). Aim: To assess the effect of IHC on bone mineral content in children without urological symptoms. Methods: Calcium excretion, BMD (by dual-energy Xray absorptiometry), and anthropometry were assessed in 175 seven-year-old children who were classified as IHC or controls. Calcium intake and physical activity were measured as confounding factors. Results: The prevalence of IHC was $17.7 \%$. Both groups (controls and IHC) showed similar baseline characteristics in terms of their anthropometry, gender distribution, and protein and calcium dietary intakes as well as physical activity scores. Urinary calciuria was independent of the calcium dietary intake and anthropometry.
\end{abstract}

BMD correlated with anthropometry and physical activity but not with calcium dietary intake. IHC children had lower whole-body BMD z-scores compared to controls. The role of $\mathrm{IHC}$ in reducing the whole-body BMD z-score was still significant even when anthropometry, physical activity, and calcium intake were included as confounders in multivariate analyses. Conclusions: The prevalence of IHC in this population of 7-year-old children was about $17 \%$. IHC diagnosis was associated with lower BMD z-scores and osteopenia in $22 \%$ of them.

(c) 2014 S. Karger AG, Basel

\section{Introduction}

The clinical consequences of adverse bone health are largely seen in old age; however, there is compelling evidence that many predisposing factors to osteoporosis arise in childhood. It is known that bone remains metabolically active throughout life and is subject to a continuous remodeling process. Thus, it is very important to

\section{KARGER}

E-Mail karger@karger.com

www.karger.com/anm
(C) 2014 S. Karger AG, Base

0250-6807/14/0644-0304\$39.50/0 
gain an adequate bone mineral content (BMC) during fetal development [1], childhood, and especially adolescence, which is a critical period for BMC acquisition [2, 3]. Some studies have estimated that an increase in total mineral content of $10 \%$ at its peak predicts a delay of 13 years in the onset of osteoporosis [4]. Genetic endowment, age, and gender, which are nonmodifiable factors, may explain up to $80 \%$ of the bone mass $[5,6]$. However, there are other factors that may influence bone mass accretion, such as sun exposure [7], hormones [8], physical exercise [9], several chronic diseases [10], and diet [1, 11] (mainly the calcium intake) [12].

One specific disease that can influence bone health is idiopathic hypercalciuria (IHC). IHC, defined as an elevated urinary calcium excretion without concomitant hypercalcemia, is a common disorder related to kidney lithiasis [13]. In children, hypercalciuria (HC) can cause a wide range of symptoms, the most common being recurrent macroscopic or microscopic hematuria. Other common manifestations in children are frequency-dysuria syndrome, recurrent urinary infections, and abdominal and lumbar pain. $\mathrm{HC}$ has also been associated with a decreased bone mineral density (BMD) [14]. Several authors have found that up to $20-30 \%$ of children with HC have a reduced BMD [15]; the impact is stronger when $\mathrm{HC}$ is persistent and is present in older children [16-18]. However, IHC may be asymptomatic during the first decades of life, and thus IHC children could remain undiagnosed for long periods. If $\mathrm{HC}$ is a deleterious factor for bone health, then screening for this condition in schoolaged children becomes important. The aim of this study was to assess the effect of IHC on bone health in a homogeneous sample of prepubertal children, controlling for calcium intake, anthropometric characteristics, and physical activity.

\section{Subjects and Methods}

\section{Subjects}

Children were recruited from the Spanish subsample of the EU Childhood Obesity Programme (CHOP) at 7 years of age. This study is an ongoing European collaborative prospective investigation of the long-term consequences of different protein intakes during the first year of life in 5 European countries (Belgium, Germany, Italy, Poland, and Spain) [19]. The aim of this study was to evaluate the influence of protein intake during the first year of life on the development of later obesity. For the present subanalysis, all children with a clinical history of urinary tract infection, hematuria, renal colic, flank pain, urolithiasis, or treatment with any drug with an action on calcium metabolism were excluded. The family history of urolithiasis was also recorded.

Lower Bone Density in 7-Year-Old

Asymptomatic Hypercalciurics

\section{Measurements}

Anthropometry

The nude weight and length of the children were determined using a SECA 701 scale (precision: $\pm 0.05 \mathrm{~kg}$; SECA, Hamburg, Germany) and a SECA 242 stadiometer (precision: $\pm 2 \mathrm{~mm}$ ), respectively. The body mass index $\left[\mathrm{BMI}=\right.$ weight $\left.(\mathrm{kg}) / \mathrm{length}(\mathrm{m})^{2}\right]$ was calculated. For analysis, z-scores were calculated according to World Health Organization (WHO) standards [20, 21] using WHO programs [22].

\section{Dietary Intake}

Calcium (mg/day) intakes were assessed via a food frequency consumption questionnaire. The questionnaire contained 19 items corresponding to milk and dairy foods. The habitual portion and frequency of consumption during the last month (times/day, times/week, or times/month) for each food item were recorded. All of the questionnaires were checked and entered into the databases by trained nutritionists. Nutritional contents were derived from either producers or national food databases $[23,24]$. The calcium intake $(\mathrm{mg} /$ day $\times \mathrm{kg}$ of body weight) was obtained as the total calcium intake, the calcium intake from milk, and the calcium intake from dairy products. To assess the role of the current dietary protein on urinary calcium excretion, we measured urea excretion as an indicator of the protein intake $[25,26]$.

\section{Physical Activity}

Physical activity was evaluated using the Physical Activity Questionnaire (PAQ-C) as defined by Kowalski et al. [27, 28]. The PAQ-C is a self-administered, 7-day recall questionnaire that measures general moderate-to-vigorous physical activity levels during the school year. It includes leisure time and daily physical activities as well as regular sports practices. We used physical activity as a confounding factor for BMD.

\section{IHC Screening and Urinalysis}

Two urine samples 1 week apart on a second morning micturition were obtained for $\mathrm{HC}$ screening after a standardized breakfast that contained dairy products (equivalent in calcium content to $200 \mathrm{~cm}^{3}$ of whole cow's milk). Samples were collected and preserved at refrigeration temperatures until analyses (4$\left.8^{\circ} \mathrm{C}\right)$. A dipstick was used to exclude the presence of an overt urinary tract infection or hematuria in every collected sample. Following the criteria reported by Stapleton et al. [29], HC was diagnosed when the value of the calcium-to-creatinine ratio ( $\mathrm{UCa} / \mathrm{UCr}$ ) was elevated in both urine collections; the HC diagnosis was made based on $\mathrm{UCa} / \mathrm{UCr}(\mathrm{mg} / \mathrm{mg})$ values above 0.21 . The cutoff criterion for an HC diagnosis was the 95th percentile value of urinary calcium excretion for a Caucasian population of 7 years of age [30]. If the values of the first 2 samples were discordant, a third urine sample was collected the following week and analyzed to define the final classification. Urea, creatinine, and calcium were determined using standardized methods. Calcium $(\mathrm{mg} / \mathrm{dl})$ was measured after acidification of the urine sample, adding $\mathrm{HCl} 6 \mathrm{~N}$ to obtain a $\mathrm{pH}$ below 2 , to dissolve the precipitated calcium. Urinary creatinine $(\mathrm{mg} / \mathrm{dl})$ was analyzed using the kinetic Jaffe reaction in an automated ADVIA 1650/Mega Bayer R (Leverkusen, Germany) in accordance with standardized protocols. Urea was measured with reagents from BeckmanCoulter (Fullerton, Calif., USA) in a Synchron Lxi ${ }^{\circledR}$ automated analyzer (Beckman-Coulter). The ratio of urea/UCr $(\mathrm{mg} / \mathrm{mg})$ 
was also calculated for each urine sample. The urine ratio values used for the statistical analyses were the means of 2 or 3 single measurements.

Dual-Energy X-Ray Absorptiometry

Fat mass and bone density were measured via dual-energy $\mathrm{X}$ ray absorptiometry (DXA) using a Lunar Prodigy Primo device. The exposure to radiation was $0.4 \mathrm{mGy}$ for the whole body (WB) and $0.9 \mathrm{mGy}$ for the lumbar spine (LS). A 76-keV X-ray source of energy was used and the precision error of the test was $1 \%$. All of the measurements were performed by the same technician to avoid interindividual variations. The fat mass index (FMI) was calculated as fat mass $(\mathrm{kg}) /$ height $(\mathrm{m})^{2}$.

The following bone densitometry variables were analyzed: WB and LS BMC (g) and bone mineral area $\left(\mathrm{BMA} ; \mathrm{cm}^{2}\right)$. The calculated variables were total and lumbar BMD $\left(\mathrm{g} / \mathrm{cm}^{2}\right)$. Specific gender $\mathrm{z}$-scores were calculated using our own current data for $\mathrm{WB}$ and LS BMD. Children with values of BMD below $-1 \mathrm{z}$-score were classified as osteopenic according to WHO recommendations [31]. As the term 'osteoporosis' is controversial in children and adolescents [32], we will use the recommended term 'low BMD for chronologic age', rather than osteoporosis, to classify children with a BMD z-score below -2 .

Bone mineral apparent density (BMAD), which is a volumetric vertebral size-independent parameter, was calculated as BMAD = LS BMC $(\mathrm{g}) /\left[\operatorname{LS} \text { BMA }\left(\mathrm{cm}^{2}\right)\right]^{1.5}[33]$.

\section{Statistical Analysis}

Data management and statistical analyses were carried out using the software package SPSS Statistics version 20.0 (IBM Corp., Armonk, N.Y., USA). Descriptive results were expressed as means $( \pm S D)$. Students $t$ tests or Mann-Whitney U tests were used for statistical comparison of quantitative variables between groups as appropriate. Pearson or Spearman correlation coefficients were used to test for linear associations among continuous variables. Differences in qualitative variables between groups were assessed using a $\chi^{2}$ test. Multiple linear regression analyses were applied to test the effect of IHC on BMD with adjustment for confounding factors such as anthropometry, calcium intake, and physical activity. $\mathrm{p}<0.05$ was considered statistically significant.

\section{Ethical Considerations}

This study was performed according to the Helsinki II declaration and was approved by the local ethical committees. All parents or caregivers of the participating infants provided written informed consent for participation in the study in accordance with the local ethical committees.

\section{Results}

\section{Study Sample}

Screening for $\mathrm{HC}$ was offered to the Spanish subsample of 213 infants at 7 years of age from October 2009 to March 2011. Of the eligible subjects, 185 agreed to participate and 176 fully adhered to the protocol of the study (i.e. provided all necessary spot urine samples to be classified as
Table 1. Anthropometric and baseline characteristics of the participants by study diagnosis group

\begin{tabular}{|c|c|c|c|}
\hline & $\begin{array}{l}\text { Control } \\
(\mathrm{n}=144)\end{array}$ & $\begin{array}{l}\text { IHC } \\
(\mathrm{n}=31)\end{array}$ & $\begin{array}{l}\mathrm{p} \\
\text { value }\end{array}$ \\
\hline Gender $(\mathrm{M} / \mathrm{F})$ & $70 / 74$ & $16 / 15$ & 0.762 \\
\hline $\begin{array}{l}\text { Family history of lithiasis, } \\
\mathrm{n}(\%)\end{array}$ & $53(52.5)$ & $15(62.5)$ & 0.375 \\
\hline Age, years & $7.02 \pm 0.13$ & $7.06 \pm 0.06$ & 0.132 \\
\hline Weight, kg & $25.58 \pm 4.67$ & $25.52 \pm 4.60$ & 0.947 \\
\hline Weight z-score & $0.66 \pm 1.12$ & $0.65 \pm 1.10$ & 0.966 \\
\hline Height, $\mathrm{cm}$ & $122.71 \pm 4.86$ & $123.32 \pm 4.44$ & 0.522 \\
\hline Height z-score & $0.26 \pm 0.90$ & $0.35 \pm 0.82$ & 0.614 \\
\hline BMI & $16.90 \pm 2.30$ & $16.72 \pm 2.45$ & 0.692 \\
\hline BMI z-score & $0.69 \pm 1.17$ & $0.60 \pm 0.27$ & 0.699 \\
\hline FMI & $3.79 \pm 1.96$ & $3.52 \pm 2.01$ & 0.507 \\
\hline FMI z-score & $4.76 \pm 1.77$ & $4.52 \pm 1.83$ & 0.502 \\
\hline
\end{tabular}

Values are presented as means \pm SD unless otherwise stated. A $\chi^{2}$ test was used for qualitative variables and Student's $t$ test was used for quantitative ones.

hypercalciuric or not) and were included. We analyzed whether the nutritional intervention conducted during the first year of life on these children could have had any influence on the key outcomes. No significant differences in calciuria or BMD were found between feeding types. A girl with a history of reflux nephropathy and microhematuria was excluded. Thus, 175 children (82\% of the Spanish subsample) were finally included in the analyses. Of those 175 children, 167 underwent DXA as well. Figure 1 shows a flowchart of the participants in this study.

\section{Prevalence of $\mathrm{HC}$}

Thirty-three of the 175 studied children required a third urine sample. A total of 31 (17.7\%) children were diagnosed with IHC. The calcium excretion ratio was 0.27 \pm 0.07 in children diagnosed with IHC and $0.10 \pm 0.05$ $(\mathrm{mg} / \mathrm{mg})$ in controls $(\mathrm{p}<0.001)$. IHC occurred similarly in males $(18.6 \%)$ and females $(16.9 \%)(p=0.762)$. All children had had normal baseline concentrations of serum calcium and acid-base balances in previous analyses (data not shown). Family histories of lithiasis were similar in children with IHC (62.5\%) and controls (52.5\%) ( $\mathrm{p}=$ $0.375)$.

\section{Effect of Anthropometric and Dietary Variables on Calciuria}

Anthropometric variables were similar in both study groups (table 1). All children were well nourished and 
Table 2. Calcium intake in children by study diagnosis group
Fig. 1. Flowchart of the participants in this study.

\begin{tabular}{llll}
\hline & $\begin{array}{l}\text { Control } \\
(\mathrm{n}=139)\end{array}$ & $\begin{array}{l}\text { IHC } \\
(\mathrm{n}=29)\end{array}$ & $\begin{array}{l}\mathrm{p} \\
\text { value }\end{array}$ \\
\hline Total calcium intake, $\mathrm{mg} / \mathrm{day}$ & $866.3 \pm 385.7$ & $797.8 \pm 456.2$ & 0.179 \\
Total calcium intake, mg/day $\times \mathrm{kg}$ & $33.3 \pm 16.9$ & $29.8 \pm 17.9$ & 0.327 \\
Calcium intake from milk, mg/day $\times \mathrm{kg}$ & $15.2 \pm 9.0$ & $12.9 \pm 8.8$ & 0.248 \\
Calcium intake from dairy products, $\mathrm{mg} /$ day $\times \mathrm{kg}$ & $16.3 \pm 11.3$ & $14.6 \pm 9.5$ & 0.422 \\
\hline
\end{tabular}

Values are presented as means \pm SD. Student's $t$ test or the Mann-Whitney U test was used as appropriate for the quantitative variables.

EU CHOP Spanish subsample

\section{Still in the study at 7 years: $n=213$ (100 boys and 113 girls)}

Did not agree to participate in complementary assessments: $n=28$

Did not provide urine samples to complete the HC diagnosis: $n=9$

Diagnosed with $\mathrm{HC}$ at 7 years: $\mathrm{n}=176$ ( 86 boys and 90 girls)

Both bone densitometry and $\mathrm{HC}$ diagnosis at 7 years: $\mathrm{n}=167$ ( 82 boys and 85 girls)

Excluded due to hematuria: $\mathrm{n}=1$
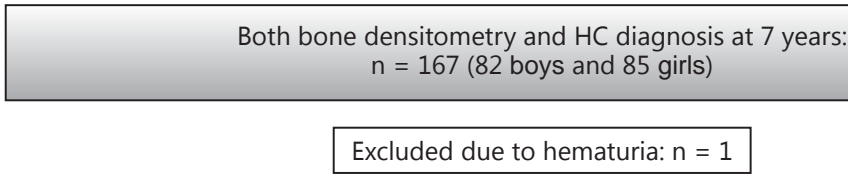

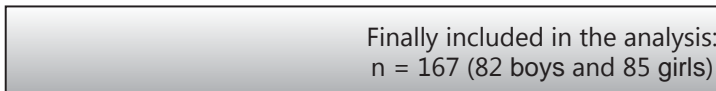

consumed an unrestricted habitual diet. No significant correlations were found between weight, height, or BMI and calciuria (data not shown).

In addition, no effect of calcium intake on calciuria was detected. First, no significant correlation between total calcium intakes $(\mathrm{mg} /$ day $\times \mathrm{kg})$ and calciuria was found $(\mathrm{r}=-0.080, \mathrm{p}=0.310)$. Moreover, there were no differences between normocalciurics and IHC children in terms of their total calcium intake or their intake of calcium from milk or dairy products (table 2), with a mean calcium intake of $854.3 \pm 398.6 \mathrm{mg} /$ day. Both groups were similarly distributed within the quartiles of total calcium intake $(34.6,13.8,25.8$, and $25.8 \%$ for the 1 st, 2 nd, $3 \mathrm{rd}$, and 4 th quartiles of $\mathrm{mg}$ of calcium/day $\times \mathrm{kg}$ ). The calcium dietary source did not influence the calciuria levels. Calcium intake estimations from milk or dairy products were similar in both groups (table 2). The urea/creatinine ratio was associated with the $\mathrm{UCa} / \mathrm{UCr}(\mathrm{r}=0.270, \mathrm{p}<0.001)$ but the urea/creatinine ratio did not significantly differ between the study groups ( $29.7 \pm 7.0$ vs. $28.5 \pm 12.9 \mathrm{mg} /$ $\mathrm{mg}$ for IHC and controls, respectively; $\mathrm{p}=0.081$ ).

\section{Effect of Anthropometry, Dietary Variables, and} Physical Activity on Bone Densitometry

Boys showed higher WB BMC (890.9 \pm 119.6 vs. 852.9 $\pm 126.9 \mathrm{~g}, \mathrm{p}=0.048)$, WB BMA $(1,055.8 \pm 103.5$ vs. $1,017.3$ 
Fig. 2. Correlation between anthropometric variables and bone densitometry. WB $\operatorname{BMD}(\mathbf{a}, \mathbf{c}, \mathbf{e}, \mathbf{g})$ and $\operatorname{LS} \operatorname{BMD}(\mathbf{b}, \mathbf{d}, \mathbf{f}, \mathbf{h})$ correlations with weight $\mathrm{z}$-score, height $\mathrm{z}$ score, BMI z-score and FMI, respectively.
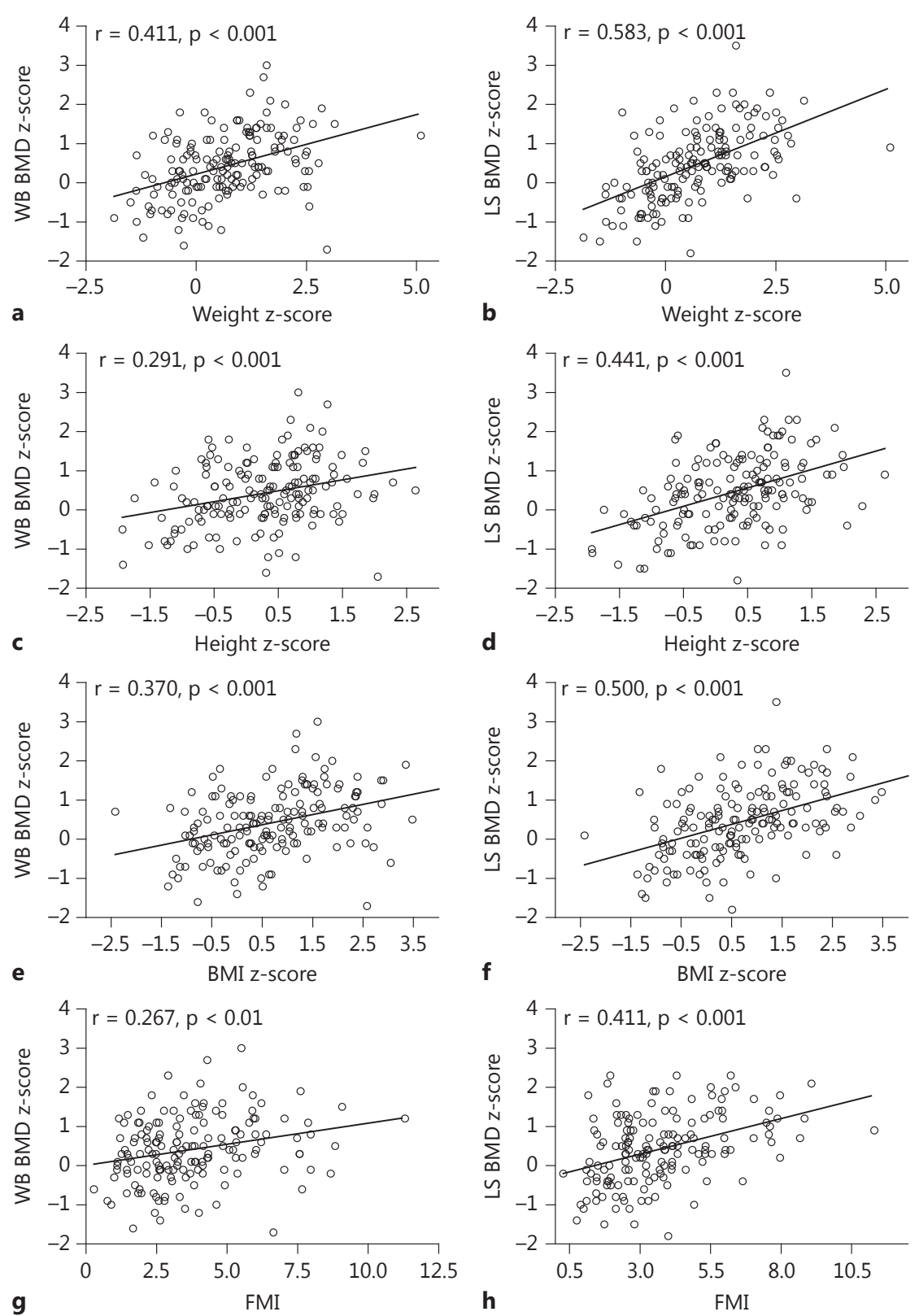

$\left.\pm 119.7 \mathrm{~cm}^{2}, \mathrm{p}=0.029\right)$, and LS BMA $(27.3 \pm 2.8$ vs. 26.0 $\left.\pm 2.7 \mathrm{~cm}^{2}, \mathrm{p}=0.003\right)$ as well as lower LS BMAD $(0.13 \pm$ 0.02 vs. $0.14 \pm 0.01 \mathrm{~g} / \mathrm{cm}^{3}, \mathrm{p}=0.014$ ) than girls. However, among all of these variables, significant differences between genders disappeared when $\mathrm{z}$-scores were analyzed.

WB BMD z-scores and LS BMD z-scores were directly associated with all anthropometric variables (fig. 2) and were not associated with the total calcium intake ( $\mathrm{mg} /$ day $\times \mathrm{kg}$ ) or the urinary urea/creatinine ratio. The physical activity (PAQ-C) score was directly associated with the WB BMC $(r=0.201, p=0.015)$ and the LS BMAD z-score $(\mathrm{r}=0.375, \mathrm{p}<0.001)$ but not with BMD or the BMD zscore. No differences were found between controls and IHC in terms of physical activity $(2.85 \pm 0.48$ vs. $2.70 \pm$ 0.48 score points for controls and IHC children, respectively; $\mathrm{p}=0.141$ ). 


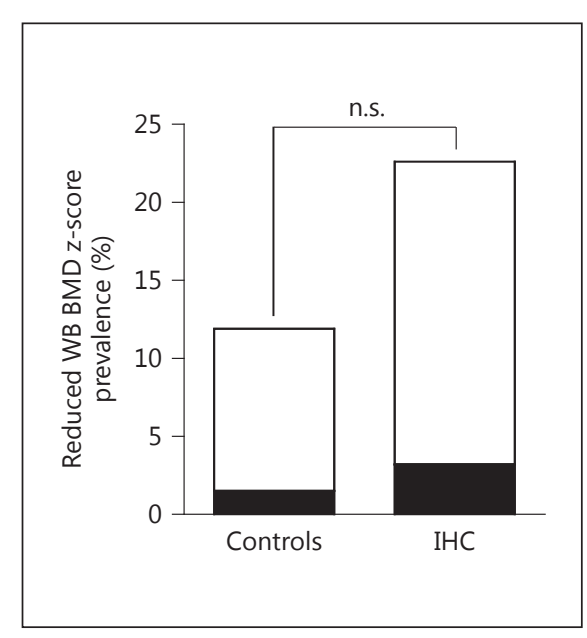

Fig. 3. Accumulated prevalence of osteopenia (WB BMD z-score lower than -1) (open bars) and low bone density for chronologic age (WB BMD z-score lower than -2) (closed bars) in control and IHC-diagnosed children. n.s. $=$ Not significant.

\section{Effect of HC on Bone Densitometry}

IHC children exhibited lower WB BMD compared to controls (table 3 ). Differences between groups were borderline significant as absolute values $(0.84 \pm 0.04$ vs. 0.83 $\left.\pm 0.04 \mathrm{~g} / \mathrm{cm}^{2}, \mathrm{p}=0.055\right)$ and significant when they were gender adjusted as z-scores $(\mathrm{p}=0.040)$ (table 3$)$. No differences were observed between study groups in any of the other bone densitometry-assessed variables (table 3 ).

Seven (22.6\%) IHC children and 16 (11.9\%) controls had a WB BMD z-score below -1 . The relative risk was 1.91 (95\% CI $0.86-4.23, \mathrm{p}=0.113)$ and did not reach statistical significance. Three children ( 2 controls and 1 IHC) showed WB BMD z-scores below -2 and could be categorized as low bone density for chronologic age. The prevalence of this feature was similar among IHC and controls (3.2 vs. $1.5 \%$ of the IHC and controls, respectively, with a relative risk of 2.27 ; $95 \%$ CI $0.21-$ 24.19) but did not reach statistical significance ( $\mathrm{p}=$ 0.498) (fig. 3).

Simple linear regression analyses revealed no effect of total calcium intake, urinary urea/creatinine ratio, or physical activity (measured as the PAQ-C score) on the WB BMD z-score. Conversely, an IHC diagnosis as well as all anthropometric variables were able to modulate the WB BMD z-score $(\mathrm{p}=0.044$ for IHC and $\mathrm{p}<0.001$ for anthropometric variables). Therefore, we included IHC diagnosis and weight $\mathrm{z}$-score (the most predictive of the anthropometric variables) in a multivariate linear regression model as independent variables and adjusted for oth-

Lower Bone Density in 7-Year-Old

Asymptomatic Hypercalciurics
Table 3. LS and WB bone densitometry parameters by study diagnosis group

\begin{tabular}{lccc}
\hline & $\begin{array}{l}\text { Control } \\
(\mathrm{n}=135)\end{array}$ & $\begin{array}{l}\mathrm{IHC} \\
(\mathrm{n}=31)\end{array}$ & $\begin{array}{l}\mathrm{p} \\
\text { value }\end{array}$ \\
\hline LS (L1 to L4) & & & \\
BMC, g & $18.56 \pm 3.10$ & $18.85 \pm 3.01$ & 0.634 \\
BA, cm & $26.40 \pm 2.60$ & $27.20 \pm 3.50$ & 0.144 \\
BMD, g/cm ${ }^{2}$ & $0.70 \pm 0.07$ & $0.69 \pm 0.08$ & 0.587 \\
BMD z-score & $0.02 \pm 1.06$ & $-0.01 \pm 0.84$ & 0.900 \\
BMAD, g/cm ${ }^{3}$ & $0.13 \pm 0.02$ & $0.13 \pm 0.02$ & 0.153 \\
BMAD z-score & $0.02 \pm 0.98$ & $-0.02 \pm 0.96$ & 0.158 \\
WB & & & \\
BMC, g & $875.0 \pm 129.6$ & $857.1 \pm 99.6$ & 0.472 \\
BA, cm & $1,036.4 \pm 116.0$ & $1,034.0 \pm 103.7$ & 0.915 \\
BMD, g/cm & $0.84 \pm 0.04$ & $0.83 \pm 0.04$ & 0.055 \\
BMD z-score & $0.09 \pm 0.99$ & $-0.31 \pm 0.88$ & 0.040 \\
\hline
\end{tabular}

Values are presented as means \pm SD. Student's t test or the Mann-Whitney U test was used as appropriate for the quantitative variables.

er confounding variables to obtain the best model to explain the WB BMD z-score (table 4). The effect of IHC diagnosis on the WB BMD z-score remained statistically significant even when we adjusted the model for the theoretically most relevant studied variables (i.e. physical activity and calcium intake). However, the most predictive model was the one that included only anthropometry and IHC diagnosis. This model was able to explain up to $18.7 \%$ of the WB BMD z-score variability (table 4 ), whereas the adjusted model (including also physical activity and calcium intake, which had no statistically significant effect) explained only up to $16.4 \%$, showing no statistical significance among the adjusted variables.

\section{Discussion}

As far as we know, this is the first study to demonstrate a reduction in BMD in children with asymptomatic IHC, which may have important implications for long-term bone health. One of the main strengths of our study is that we controlled the most important factors that modulate urinary calcium excretion and BMD.

The IHC prevalence in our study sample was in the higher range of the already reported prevalences in Spanish children $(7.8$ and $16 \%)$ [34, 35]. Studies in children have not conclusively demonstrated a clear difference between the different subtypes of HC (resorptive, renal, and absorptive), overcoming classification modifications in the same 
Table 4. Effect of IHC on the WB BMD z-score

\begin{tabular}{|c|c|c|c|c|c|}
\hline & $\mathrm{n}$ & Estimate & $95 \% \mathrm{CI}$ & $\mathrm{p}$ & $\mathrm{R}^{2}$ \\
\hline \multicolumn{6}{|l|}{ Model adjusted for anthropometry } \\
\hline Weight z-score & 164 & 0.361 & 0.240 to 0.482 & $<0.001$ & 0.187 \\
\hline IHC (yes vs. no) & & -0.379 & -0.727 to -0.032 & 0.033 & \\
\hline \multicolumn{6}{|c|}{ Model adjusted for anthropometry, physical activity, and calcium intake } \\
\hline Weight z-score & 145 & 0.240 & 0.121 to 0.359 & $<0.001$ & 0.164 \\
\hline IHC (yes vs. no) & & -0.351 & -0.681 to -0.021 & 0.037 & \\
\hline PAQ-C score & & -0.248 & -0.023 to 0.519 & 0.072 & \\
\hline Calcium intake, $\mathrm{mg} /$ day $\times \mathrm{kg}$ & & -0.004 & -0.012 to 0.004 & 0.306 & \\
\hline
\end{tabular}

children over the years [14]. Patients with resorptive HC present major bone damage, but this is present also in the other subtypes [36, 37]. For this reason, we were interested in evaluating children with any subtype of IHC, and therefore we used a general protocol for $\mathrm{HC}$ diagnosis without performing specific tests to determine the different pathophysiological subtypes described within IHC.

\section{Urinary Calcium Excretion Evaluation}

Several factors such as age, body size, and the intake of a number of nutrients influence urinary calcium excretion in humans [38-40]. It is known that a positive association exists between BMI and urinary excretion of sodium, calcium, uric acid, and citrate. Furthermore, overweight has been associated with an increased risk of calcium stones in both adults and children with HC [41]. In our study, we found no relationship between anthropometric variables and calciuria, possibly because all children were the same age and had similar anthropometric characteristics.

The most important dietary factor affecting calciuria is calcium intake, but large epidemiological studies have shown that significant differences in dietary calcium intake have little influence on the level of calciuria in either normal subjects or those with kidney stones [42]. In our study, children with IHC showed daily calcium intakes similar to those of controls, and there was no association between calcium intake and urinary excretion. On the other hand, a high consumption of animal proteins could cause acid overload, which would inhibit the renal reabsorption of calcium and increase its urinary excretion [43]. To control the possible effect of protein intake on calciuria, we analyzed urinary urea as the urea/creatinine ratio has been demonstrated to be an accurate indicator of protein intake $[25,26,34]$. Although we found a slight correlation between urea/creatinine and calciuria, both controls and IHC had similar urea excretion levels. Therefore, we assumed no significant bias in the classification of children as IHC secondary to dietetic factors, as the intakes of calcium as well as proteins were similar in the two diagnosis groups.

\section{Influence of HC on Bone Health}

In this study, we also controlled many of the factors that may influence BMD, such as anthropometric characteristics, dietary factors, and physical activity. Throughout childhood, the length and width of bones increase, the cortical thickness increases, and there is a dramatic increase in bone mass as well as a significant increase in bone density. All of these processes are influenced by genetic, hormonal, and environmental factors. The hormonal effect had little influence on our study because our children were all in the prepubertal stage. Adequate calcium and vitamin $\mathrm{D}$ availability together with regular physical activity are among the most important environmental factors for the optimal accrual of bone mineral mass and density [44]. A meta-analysis of 19 randomized controlled trials including 2,859 healthy children aged 3-18 years showed a positive effect of calcium supplementation on the total body BMC with doses ranging between 300 and 1,200 mg/day [45]. Moreover, an animal protein-rich diet produces an acid overload caused by mobilization of the bone buffer system, which favors a loss of calcium deposits, together with renal physiology changes that cause glomerular hyperfiltration and inhibit tubular reabsorption of calcium, thus increasing the calciuria. This complex mechanism causes a negative calcium balance and bone loss [15]. In relation to these dietetic factors, in our study we did not find associations between calcium and protein intake and BMD, probably because they were within the normal range for that age. 
On the other hand, it is well known that exercise exerts a positive effect on bone mass. Physical activity during early childhood and adolescence is an important predictor of the bone mass peak, which may account for up to $17 \%$ of the variance in BMD between individuals in their late 20s [6]. In our study, physical activity levels were similar in both groups (IHC and controls), but, as expected, we found direct associations between physical activity and WB BMC as well as with the LS BMAD z-score; therefore, we adjusted the effect of HC on BMD for physical activity in multivariate analyses.

A low weight and a low BMI are well-documented risk factors for future fractures, whereas a high BMI appears to be protective. Body weight is positively associated with WB BMD in adults, possibly as a consequence of enhanced mechanical strain. Accordingly, we also observed an association between anthropometric variables and bone densitometry in the 7-year-old children, with weight being the most highly correlated variable.

It is worth commenting that the LS BMD might be affected by the above-mentioned factors in a different way than the rest of the body is not. LS BMD mainly consists of trabecular bone, whereas WB BMD consists of $80 \%$ cortical bone. Thus, LS BMD is mostly affected by weight bearing, whereas WB BMD is mostly affected by nutrition and physical activity. Our study was consistent with these characteristics and mechanisms based on the higher correlations observed between anthropometric variables and LS versus WB densitometry (fig. 2).

It is well known that there is renal loss of calcium in patients with $\mathrm{HC}$ caused by a defect in the reabsorption of filtered calcium, even among children with increased intestinal absorption. This effect leads to a negative balance of calcium in most of these patients, which promotes bone loss [46]. Bone loss in children with IHC can result from increased bone resorption, decreased bone formation, or both. The main mechanism is controversial, and several authors argue that bone loss is consistent with increased bone resorption and/or turnover and could be precociously detected in trabecular bone in the LS [15], but others advocate the notion that the low BMD is due principally to a suppression of bone formation, especially in patients with absorptive HC. Therefore, a common finding in studies on IHC children is a frequent decrease in BMD. Thus, a current concern is the contribution of persistent HC to a diminished bone mass. In 1992, Perrone et al. [17] examined 20 children with IHC resulting from increased intestinal absorption of calcium. Among these children, 4 (20\%) showed a reduced LS BMD. In a previous study, we, like other authors, observed a lower BMD in patients with

Lower Bone Density in 7-Year-Old

Asymptomatic Hypercalciurics sustained $\mathrm{HC}$ compared to cases with rare or intermittent HC $[17,18]$. In addition, different authors have reported inverse associations between BMD and age in patients with IHC [16]. Thus, it seems that bone loss may be influenced by the magnitude and the persistence of elevated calciuria, supporting the idea that prolonged periods of $\mathrm{HC}$ are needed to affect the bone structure. This may explain why children with asymptomatic $\mathrm{HC}$, where the calciuria intensity is probably lower, would have less skeletal involvement. All of these features are relevant for the interpretation of our results. We found a significant reduction of WB BMD z-scores among IHC children, with a slight reduction in the lumbar area that did not reach statistical significance compared to controls. This fact could be attributed to a possibly lower proportion of patients with resorptive IHC in our series (which is more symptomatic than absorptive IHC) and therefore less trabecular bone involvement. The reported prevalence of osteopenia in symptomatic HC children ranges from 30 to $47 \%$ [15]. We found a slightly lower prevalence of osteopenia (22\%) probably because our IHC children were younger and asymptomatic. Despite the absence of a statistical difference between IHC and controls in the prevalence of serious bone demineralization (3.2 vs. $1.5 \%$ ), the fact that the WB BMD z-scores of asymptomatic IHC children were lower at 7 years of age is of great importance due to the long-term possible consequences if $\mathrm{HC}$ persists. It is also noteworthy that most of the relevant factors affecting BMD were controlled in our study, and even analyses adjusting for those factors showed a reduced BMD in IHC children. Among those factors, the ones most related to BMD were anthropometry and physical activity. Our multivariate analyses demonstrated that those factors did not interfere with the effect of $\mathrm{HC}$ on bone mineralization.

\section{Strengths and Limitations}

As previously stated, in our study we controlled results for the most relevant factors that modulate urinary calcium excretion and BMD. However, a limitation might be that we did not control the dietary intake of vitamin $\mathrm{D}$ and therefore we have to assume a similar effect in all children in our study which was conducted in the same Mediterranean geographical area. We diagnosed HC including all physiopathological subtypes. As patients with resorptive HC present major bone damage, our selection of patients could have modulated our findings. Other limitations we have to assume are related to the single age and time point assessment. We included only 7-year-old children and performed evaluations as transversal observations. This design did not allow us to determine whether the observed 
differences in bone mineralization between normocalciurics and hypercalciurics disappeared or were enhanced at further ages. Despite this limitation, our aim was to detect bone affectation in an early age period, and for this reason we selected children in the prepubertal period.

\section{Conclusions}

We found a nondepreciable $17 \%$ of IHC children among an apparently healthy population of 7-year-old children. IHC children showed reduced WB BMD z-scores, with $22 \%$ of them at the osteopenic level. We think that screening for $\mathrm{HC}$ in school-aged children could be important because the reduction of bone mass seems to be precocious, already present in previously undiagnosed children, suggesting that asymptomatic IHC could act as a detrimental factor influencing BMD in the future. The natural course of $\mathrm{HC}$-associated low bone density requires further evaluation. Longitudinal studies in this pediatric population will help us to address the significance of this prepubertal bone loss for the risk of fractures in adulthood.

\section{European Childhood Obesity Project Group}

J. Beyer, M. Fritsch, G. Haile, U. Handel, I. Hannibal, B. Koletzko, S. Kreichauf, I. Pawellek, S. Schiess, S. Verwied-Jorky, R. von Kries, and M. Weber (Children's University Hospital, University of Munich Medical Center, Munich, Germany); A. Dobrzańska,
D. Gruszfeld, R. Janas, A. Wierzbicka, P. Socha, A. Stolarczyk, and J. Socha (Children's Memorial Health Institute, Warsaw, Poland); C. Carlier, E. Dain, P. Goyens, J.N. Van Hees, J. Hoyos, J.P. Langhendries, F. Martin, P. Poncelet, and A. Xhonneux (ULB, Bruxelles, Belgium, and CHC St. Vincent, Liège-Rocourt, Belgium); E. Perrin (Danone Research Centre for Specialised Nutrition, Schiphol, The Netherlands), and C. Agostoni, M. Giovannini, A. Re Dionigi, E. Riva, S. Scaglioni, F. Vecchi, E. Verducci (University of Milan).

\section{Acknowledgement}

We are very grateful to the families taking enthusiastically part in the Childhood Obesity Project. We gratefully acknowledge Francisco Javier Villalba Rubio (from IDI, Hospital Universitari de Tarragona Joan XXIII) for his work performing DXA measurements and Pol Solé Navais (URV) for his help on data introduction.

\section{Disclosure Statement}

The studies reported herein have been carried out with partial financial support from the European Union, within the 5th Framework Programme, research grants No. QLRT-2001-00389 and QLK1-CT-2002-30582, the 6th Framework Programme, contract No. 007036, and the 7th Framework Programme (FP7/2008-2013), under grant agreement No. 212652 (NUTRIMENTHE Project 'The Effect of Diet on the Mental Performance of Children') (FP7/2007-2013), and under the grant agreement No. 289346 (project EarlyNutrition). This paper does not necessarily reflect the views of the Commission and in no way anticipates the future policy in this area.

\section{References}

$\rightarrow 1$ Specker B: Nutrition influences bone development from infancy through toddler years. J Nutr 2004;134:691S-695S.

2 Bailey DA, Martin AD, McKay HA, Whiting S, Mirwald R: Calcium accretion in girls and boys during puberty: a longitudinal analysis. J Bone Miner Res 2000;15:2245-2250.

-3 Aguado Henche S, Rodriguez Torres R, Clemente de Arriba C, Gomez Pellico L: Total and regional bone mineral content in healthy Spanish subjects by dual-energy X-ray absorptiometry. Skeletal Radiol 2008;37:1025-1032.

-4 Hernandez CJ, Beaupré GS CD: A theoretical analysis of the relative influences of peak $\mathrm{BMD}$, age-related bone loss and menopause on the development of osteoporosis. Osteoporos Int 2003;14:843-847.

5 Hui SL, Koller DL, Foroud TM, Econs MJ, Johnston CC, Peacock M: Heritability of changes in bone size and bone mass with age in premenopausal white sisters. J Bone Miner Res 2006;21:1121-1125.
6 Davies JH, Evans BA, Gregory JW: Bone mass acquisition in healthy children. Arch Dis Child 2005;90:373-378.

7 Valimaki VV, Alfthan H, Lehmuskallio E, et al: Vitamin D status as a determinant of peak bone mass in young Finnish men. J Clin Endocrinol Metab 2004;89:76-80.

8 Sneppen SB, Hoeck HC, Kollerup G, Sorensen $\mathrm{OH}$, Laurberg P, Feldt-Rasmussen U: Bone mineral content and bone metabolism during physiological $\mathrm{GH}$ treatment in $\mathrm{GH}$ deficient adults - an 18-month randomised, placebo-controlled, double blinded trial. Eur J Endocrinol 2002;146:187-195.

-9 Martyn-St James M, Carroll S: High-intensity resistance training and postmenopausal bone loss: a meta-analysis. Osteoporos Int 2006; 17 : 1225-1240.

10 Secondi MV, Floresa L, Perez M, Ramírez S: Alteración de la masa ósea en la infancia y en la adolescencia: revisión bibliográfica. Rev Hosp Mat Inf Ramón Sardá 2009;28:78-85.
11 Greer FR, Krebs NF; National Academy of Pediatrics Committee on Nutrition: Optimizing bone health and calcium intakes of infants, children, and adolescents. Pediatrics 2006; 117:578-585.

12 Cadogan J, Eastell R, Jones N, Barker ME Milk intake and bone mineral acquisition in adolescent girls: randomised, controlled intervention trial. BMJ 1997;315:1255-1260.

13 Escribano Subias J, Vicente Rodriguez M, Feliu Rovira A, Balaguer Santamaria A, Colomer Kammuller L, Castejon Sanz E: Idiopathic hypercalciuria: clinical manifestation, outcome and risk for urolithiasis in children. An Esp Pediatr 1997;46:161-166.

14 Srivastava T, Schwaderer A: Diagnosis and management of hypercalciuria in children. Curr Opin Pediatr 2009;21:214-219.

15 Zerwekh JE: Bone disease and hypercalciuria in children. Pediatr Nephrol 2010;25:395401. 
16 Garcia-Nieto V, Navarro JF, Ferrandez C: Bone loss in children with idiopathic hypercalciuria. Nephron 1998;78:341-342.

17 Perrone HC, Marone MMS, Bianco AC, Toporovski J, Malvestiti LF, Schor N: Bone mineral density in hypercalciuric children: a 5 year follow-up. Pediatr Nephrol 1995;9:121.

18 Hernandez A, Escribano J, Salvado O, Pagone F: Osteopenia en niños con hipercalciuria idiopática persistente. Nefrologia 2007;27:C60.

19 Koletzko B, von Kries R, Closa R, et al: Lower protein in infant formula is associated with lower weight up to age $2 \mathrm{y}$ : a randomized clinical trial. Am J Clin Nutr 2009;89:1836-1845.

20 WHO Multicentre Growth Reference Study Group: WHO Child Growth Standards based on length/height, weight and age. Acta Paediatr Suppl 2006;450:S76-S85.

21 WHO Multicenter Growth Reference Study Group: WHO Child Growth Standards: methods and development - head circumference-for-age, arm circumference-for-age, triceps skinfold-for-age and subscapular skinfold-for-age. Geneva, WHO, 2007.

22 WHO Multicentre Growth Reference Study Group: WHO Anthro software for PC. Geneva, WHO, 2009.

23 Centre d'Ensenyament Superior de Nutrició i Dietètica: Tablas de Composición de Alimentos. Barcelona, Edicions Universitat de Barcelona, 2002.

24 Mataix J, Mañas M, Llopis J, Martínez de Victoria E, Sánchez JJ, Borregon A: Tabla de Composición de Alimentos Españoles. Granada, Universidad de Granada, 2003.

-25 Frey J, Daudon M, Raby N, et al: Clinical value of urinary biochemical parameters. Ann Biol Clin (Paris) 2001;59:13-25.

-26 Polito C, Signoriello G, Andreoli S, La Manna A: Urinary urea excretion in idiopathic hypercalciuria of children. J Pediatr Urol 2006; 2:419-423.
27 Kowalski K, Crocker P, Donen R: The Physical Activity Questionnaire for Older Children (PAQ-C) and Adolescents (PAQ-A) Manual. Saskatoon, University of Saskatchewan, 2004.

28 Janz KF, Lutuchy EM, Wenthe P, Levy SM: Measuring activity in children and adolescents using self-report: PAQ-C and PAQ-A. Med Sci Sports Exerc 2008;40:767-772.

29 Stapleton FB, Noe HN, Jerkins G, Roy S 3rd: Urinary excretion of calcium following an oral calcium loading test in healthy children. Pediatrics 1982;69:594-597.

30 So NP, Osorio AV, Simon SD, Alon US: Normal urinary calcium/creatinine ratios in African-American and Caucasian children. Pediatr Nephrol 2001;16:133-139.

31 Vitamin and mineral requirements in human nutrition. Rep joint FAO/WHO expert consult. Bangkok, September 21-30, 1998.

32 Gordon CM, Bachrach LK, Carpenter TO, et al: Dual energy X-ray absorptiometry interpretation and reporting in children and adolescents: the 2007 ISCD Pediatric Official Positions. J Clin Densitom 2008;11:43-58.

33 Carter DR, Bouxsein ML, Marcus R: New approaches for interpreting projected bone densitometry data. J Bone Miner Res 1992;7:137145.

34 Garcia-Nieto V, Siverio B, Monge M, Toledo C, Molini N: Urinary calcium excretion in children with vesicoureteral reflux. Nephrol Dial Transplant 2003;18:507-511.

35 Melian JS, Garcia Nieto V, Sosa AM: Inheritance and prevalence of hypercalciuria in the children from the island of La Gomera. Nefrologia 2000;20:510-516.

-36 Pak CY, Heller HJ, Pearle MS, Odvina C V, Poindexter JR, Peterson RD: Prevention of stone formation and bone loss in absorptive hypercalciuria by combined dietary and pharmacological interventions. J Urol 2003;169: 465-469.
37 Pietschmann F, Breslau NA, Pak CY: Reduced vertebral bone density in hypercalciuric nephrolithiasis. J Bone Miner Res 1992;7: 1383-1388.

38 Esbjörner E, Jones IL: Urinary calcium excretion in Swedish children. Acta Paediatr 1995; 84:156-159.

39 Reusz GS, Dobos M, Byrd D, Sallay P, Miltényi M, Tulassay T: Urinary calcium and oxalate excretion in children. Pediatr Nephrol 1995;9:39-44.

40 Escribano J, Balaguer A, Roqué I, Figuls M, Feliu A, Ferre N: Dietary interventions for preventing complications in idiopathic hypercalciuria. Cochrane Database Syst Rev 2014;2:CD006022.

41 Leonetti F, Dussol B, Berthezene P, Thirion X, Berland Y: Dietary and urinary risk factors for stones in idiopathic calcium stone formers compared with healthy subjects. Nephrol Dial Transplant 1998;13:617-622.

42 Taylor EN, Fung TT, Curhan GC: DASHstyle diet associates with reduced risk for kidney stones. J Am Soc Nephrol 2009;20:22532259.

43 Moe OW: Kidney stones: pathophysiology and medical management. Lancet 2006;367: 333-344.

44 Bianchi ML: Osteoporosis in children and adolescents. Bone 2007;41:486-495.

45 Winzenberg T, Shaw K, Fryer J, Jones G: Effects of calcium supplementation on bone density in healthy children: meta-analysis of randomised controlled trials. BMJ 2006;333: 775 .

46 Worcester EM, Coe FL: New insights into the pathogenesis of idiopathic hypercalciuria. Semin Nephrol 2008;28:120-132. 